\title{
Growth Hormone Secretagogues and the Regulation of Calcium Signaling in Muscle
}

\author{
Elena Bresciani *(D), Laura Rizzi ${ }^{D}$, Silvia Coco, Laura Molteni, Ramona Meanti, Vittorio Locatelli \\ and Antonio Torsello
}

School of Medicine and Surgery, University of Milano-Bicocca, 20900 Monza, Italy

* Correspondence: elena.bresciani@unimib.it

Received: 1 August 2019; Accepted: 3 September 2019; Published: 5 September 2019

\begin{abstract}
Growth hormone secretagogues (GHS) are a family of synthetic molecules, first discovered in the late 1970s for their ability to stimulate growth hormone (GH) release. Many effects of GHS are mediated by binding to GHS-R1a, the receptor for the endogenous hormone ghrelin, a 28-amino acid peptide isolated from the stomach. Besides endocrine functions, both ghrelin and GHS are endowed with some relevant extraendocrine properties, including stimulation of food intake, anticonvulsant and anti-inflammatory effects, and protection of muscle tissue in different pathological conditions. In particular, ghrelin and GHS inhibit cardiomyocyte and endothelial cell apoptosis and improve cardiac left ventricular function during ischemia-reperfusion injury. Moreover, in a model of cisplatin-induced cachexia, GHS protect skeletal muscle from mitochondrial damage and improve lean mass recovery. Most of these effects are mediated by GHS ability to preserve intracellular $\mathrm{Ca}^{2+}$ homeostasis. In this review, we address the muscle-specific protective effects of GHS mediated by $\mathrm{Ca}^{2+}$ regulation, but also highlight recent findings of their therapeutic potential in pathological conditions characterized by skeletal or cardiac muscle impairment.
\end{abstract}

Keywords: calcium $\left(\mathrm{Ca}^{2+}\right)$ homeostasis; GHS (growth hormone secretagogues); cardiac ischemia/reperfusion (I/R) damage; cachexia; skeletal muscle wasting

\section{Introduction}

Calcium $\left(\mathrm{Ca}^{2+}\right)$ is an intracellular messenger that governs a variety of cellular processes such as gene transcription, cell proliferation, programmed cell death, neurotransmission, and muscle contraction and functioning [1]. In skeletal muscle fibers, $\mathrm{Ca}^{2+}$ pivotal role is the regulation of the excitation-contraction coupling process, but it is also involved in protein synthesis and degradation, fiber type shifting, activation of $\mathrm{Ca}^{2+}$-regulated proteases and transcription factors, and mitochondrial adaptation, plasticity, and respiration [1]. In the myofibers, acetylcholine interaction with its receptor via $\alpha$-motoneurons generates a depolarizing wave, mediated by voltage-gated sodium channels, which results in L-type $\mathrm{Ca}^{2+}$ channel activation (CaV1.1 or dihydropyridine receptor, DHPR). The subsequent entry of $\mathrm{Ca}^{2+}$ controls the ryanodine receptors (RyR) in the sarcoplasmic reticulum, allowing a huge release of $\mathrm{Ca}^{2+}$ that ultimately favors the cross-bridge between actin and myosin filaments. This process is essential for the sarcomere shortening, the contraction of myofibers, and thus the muscular force generation [1].

The maintenance of adequate $\mathrm{Ca}^{2+}$ concentrations across extracellular and intracellular compartments of the muscle cell is crucial for sustained contractility. In resting muscle fibers, free $\mathrm{Ca}^{2+}$ concentrations are strictly regulated and maintained at low levels $(20-50 \mathrm{nM})$, primarily by the activity of the sarcoplasmic reticulum that accumulates huge amounts of $\mathrm{Ca}^{2+}$ ions, which are quickly released in the cytosol upon the arrival of action potentials [1]. The prompt restoration of physiological cytosolic $\mathrm{Ca}^{2+}$ concentration is operated, beside sarcoplasmic reticulum, also by the intervention of 
$\mathrm{Ca}^{2+}$ channels, exchangers, pumps, transporters, and binding proteins [1]. Dysregulation of $\mathrm{Ca}^{2+}$ signaling/homeostasis represents a common underlying phenomenon in the pathophysiology of many conditions affecting the muscle, such as myopathies and systemic disorders, as well as hypoxia, sepsis, cachexia, sarcopenia, heart failure, and dystrophy [2,3].

Growth hormone secretagogues (GHS) are a family of synthetic compounds, characterized by heterogeneous chemical structures, originally discovered for their GH-releasing properties [4]. Later studies demonstrated that GHS mimic the activity of ghrelin, an endogenous 28-amino acid peptide released primarily by the stomach $[5,6]$. Ghrelin is known as the "hunger hormone" because it stimulates feeding behavior, but it is also involved in the regulation of gastrointestinal motility and energy and glucose homeostasis [5,6]. However, besides the endocrine activities, ghrelin displays a variety of extraendocrine properties shared also by many GHS, targeting peripheral tissues and the central nervous system [7-12]. Ghrelin and GHS actions are mainly mediated by binding to the GHS receptor type 1a (GHS-R1a), a G-coupled receptor, and inducing intracellular $\mathrm{Ca}^{2+}$ mobilization [13]. Among the peripheral actions, a large body of evidence indicates that ghrelin and GHS improve muscle function in several pathological conditions. Indeed, they show cardioprotective activity both in vitro and in vivo in different experimental models [14-19], and humans [20,21]. Interestingly, GHS treatment prevents cisplatin-induced damage in rat skeletal muscles [22,23]. The mechanisms accounting for the beneficial impact of ghrelin and GHS on muscle cells have been only partially elucidated and different hypothesis have been proposed, including the ability to: (i) inhibit apoptosis; (ii) increase nitric oxide (NO) release; (iii) counteract the activity of pro-inflammatory cytokines; (iv) inhibit reactive oxygen species (ROS) generation; and (v) prevent proteasome activity [11,12,22-25]. In recent years, research has focused on GHS and ghrelin effects on $\mathrm{Ca}^{2+}$ homeostasis, speculating that the regulation of this process could play a key role in mediating their specific muscle beneficial activity. This review aims to present the most recent data showing the GHS involvement in $\mathrm{Ca}^{2+}$ homeostasis, highlighting their therapeutic potential in different conditions characterized by muscle impairment.

\section{Growth Hormone Secretagogues (GHS)}

\subsection{GHS Discovery and State of Art}

The acronym GHS indicates a large family of synthetic compounds with a heterogeneous chemical structure, which includes peptidyl, peptidomimetic, and nonpeptidic moieties. They were originally developed in the late 1970s for their capability to stimulate GH secretion, both in vitro and in vivo, and the great interest toward their endocrine activity ensued from the lack of knowledge of the natural hypothalamic hormone that stimulates GH secretion. Indeed, it is noteworthy that the endogenous growth hormone-releasing hormone (GHRH) was discovered only about 10 years later, in 1982 [26]. Originally, this class of molecules was denominated growth hormone-releasing peptides (GHRP) because of their peptidyl structure, characterized by the presence of tryptophan (Trp) residues [4]; nowadays, these compounds are preferentially designated GHS, in order to include the nonpeptidic compounds, developed in more recent years and endowed with a better oral bioavailability. The first GHRP was synthesized by C.Y. Bowers, starting from the sequence of metenkephalin. Bowers reported that the peptide Tyr-DTrp ${ }^{2}$-Gly-Phe-MetNH2 (DTrp²-GHRP), containing dextrorotary (D)-amino acids, weakly stimulated GH release from rat pituitary cells [27]. A few months later, Bowers published the first GHRP with relevant GH-stimulating activity, the hexapeptide His-DTrp-Ala-Trp-DPhe-Lys-NH2, named GHRP-6. GHRP-6 effectively stimulated GH secretion in vitro from pituitary cells, and also in vivo in the rat. Upon GHRH identification, several studies were performed to investigate the relationship between GHRH and GHS. It was concluded that GHS have a dual site of action, at the pituitary and hypothalamic levels, and that their activity was synergic with GHRH, but on different receptors. Results demonstrated that GHS have a mechanism of action involving the activation

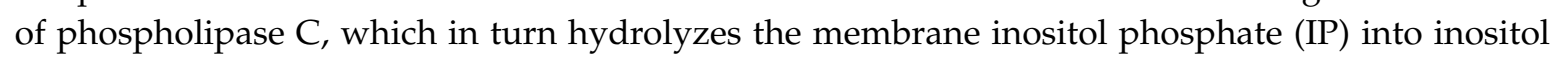
triphosphate $\left(\mathrm{IP}_{3}\right)$ and diacylglycerol (DAG); $\mathrm{IP}_{3}$ hence facilitates $\mathrm{Ca}^{2+}$ release from intracellular $\mathrm{Ca}^{2+}$ 
stores, causing GH secretion [4]. It soon became clear that the GHS mechanism of action was quite different from that of GHRH, whose binding to its specific seven-transmembrane G protein-coupled receptor (GPCR) activates the cAMP protein kinase A signaling pathway [28]. Further data supporting that GHS and GHRH activate different receptors were provided by this simple demonstration: the first challenge with GHRH blunts the effects of a second stimulation with GHRH, whereas the first challenge with GHS does not affect GHRH effects, and when administered in combination, GHS synergizes with GHRH on GH release [29-33]. Moreover, GHS administration did not activate the physiological negative feedback mechanisms involving somatostatin and insulin-like growth factor-I (IGF-I) release [27].

However, although the knowledge of GHS endocrine effects is continuously growing, the comprehension of their exact mechanism of action remains largely unclear. Only twenty years after the discovery of GHRP-6, a specific receptor for the GHS was finally characterized. In 1996, using the radiolabeled peptidomimetic compound MK-0677, a group of researchers at the Merck company found that GHS bind a receptor (GHS-R1a) that is coupled with members of the $\mathrm{G}_{\mathrm{q}} / \mathrm{i}$ family, and that activates the phospholipase C, according to early research $[13,27]$. The GHS-R is synthesized in two isoforms, deriving by an alternative splicing process. The GHS-R1a is a seven-transmembrane G protein-coupled receptor mediating most GHS actions, characterized by a high level of constitutive activity and the ability to form heterodimers with other GPCRs. The GHS receptor 1b (GHS-R1b), instead, is a truncated form of GHS-R1a, encompassing only the first five transmembrane domains. GHS-R1b does not bind GHS and is devoid of any activity on the somatotropic axis, although it is expressed by almost every tissue in the organism [13]. The dichotomy between GHS-R1b wide expression and the failure of promoting GHS biological activity has led to better investigation of its physiological significance, that however still remains largely unclear. Preliminary studies have indicated a possible dominant-negative effect of GHS-R1b, which could rely on its ability to sequestrate the GHS-R1a into intracellular compartments or to stabilize the GHS-R1a in a non-signaling conformation [34]. Nonetheless, new research supports the notion that GHS-R1b could have a more sophisticated activity on GHS-R1a signaling. First, it promotes GHS-R1a trafficking to the plasma membrane with an efficiency that depends on the specific relative GHS-R1b/GHS-R1a expression ratio: increasing the ratio, mobilization of GHS-R1a to the plasma membrane is progressively lost. Second, GHS-R1b impairs GHS-R1a signaling upon oligomerization at the plasma membrane level. Thus, it seems that the relative expression of GHS-R1b not only regulates the efficacy of GHS-R1a signaling, but also assesses the ability of GHS-R1a to form oligomeric complexes with other receptors [34].

The endogenous ligand of the GHS-R1a, ghrelin, was unexpectedly isolated from the stomach, where it is predominantly produced by a distinct group of enteroendocrine ghrelinergic cells in the gastric mucosa. Ghrelin is a 28 -amino acid peptide that possesses a fatty acid side-chain (preferably C8 or C10) on the serine in position 3. This acylation is essential for binding to GHS-R1a and ghrelin biological functions, including the stimulation of GH secretion and food intake. This rare post-translational modification is achieved by the enzyme ghrelin O-acyl-transferase (GOAT), a member of the membrane-bound O-acyltransferase (MBOAT) family [6,12]. Des-acyl ghrelin (D-AG) or unacylated ghrelin (UAC) is an isoform of ghrelin lacking the acylation and unable to bind the GHS-R1a. Generally considered an inactive product of ghrelin degradation, D-AG has emerged to be an active peptide that, in some cases, shows effects similar to those of ghrelin, but in other instances has different activities [35]. Beginning from the discovery of ghrelin and des-acyl ghrelin, several researches were aimed to explore their physiological role and their involvement in different pathological conditions. However, it became soon evident that their potential clinical use was limited because of the short half-life and the need for parenteral administration. Hence, new agonists and antagonists of the GHS-R1a were developed with better pharmacokinetic profile and oral availability. These ghrelin analogs were intended to be used in specific therapeutic areas such as aging, obesity, cachexia, inflammatory, intestinal and neurodegenerative diseases, muscle, bone and glucose metabolism disorders, cardiac and kidney failure, and to prevent alcohol-seeking behaviors. 
In consideration of the pleiotropic peripheral and central effects of ghrelin and ligands of the GHS-R1a, clinical studies are currently ongoing in different pathological fields. Anamorelin and ulimorelin are two agonists of the ghrelin receptor presently under clinical development. Anamorelin is an orally active, high-affinity, selective agonist of the GHS-R1a. Phase 3 clinical studies in patients with advanced non-small cell lung cancer and cachexia reported that anamorelin administration for 12 weeks increased lean body mass (LBM) and body weight, improving some symptoms of anorexia/cachexia [36]. Ulimorelin (TZP-101) is under investigation in diabetic patients with gastroparesis for its capability to stimulate gastric emptying and improve upper gastrointestinal symptoms [37]. On the other side, PF-5190457 is a GHS-R1a inverse agonist currently undergoing clinical development for the treatment of alcohol abuse disorder [38].

\subsection{GHS Effects on Muscle}

Several severe pathological conditions, from cardiovascular disease to cachexia and aging, recognize muscle damage as a causal or contributing factor $[39,40]$. Various experimental evidences indicating the capability of GHS to prevent muscle damage or provide a protective outcome in vitro or in vivo have attracted the attention of the scientific community, and a relevant number of researches has been published in recent years on this topic. However, studies investigating the link between GHS protective activity on cardiac and/or skeletal muscle and the regulation of $\mathrm{Ca}^{2+}$ homeostasis have focused mainly on two molecules: hexarelin, a well-known peptidyl GHS [22,23,41,42], and JMV2894, a novel peptidomimetic GHS [22,23].

\subsubsection{GHS Actions on Cardiac Muscle}

Cardiac ischemia is the leading cause of mortality in the world. It is primarily caused by a reduction of blood flow in the cardiac coronary arteries [43]. Hence, the primary therapeutic intervention is to restore heart reperfusion. Nevertheless, it is well known that this maneuver can cause additional injury to the cardiac tissue. Ischemia/reperfusion (I/R) damage has been long investigated and entails multiple molecular and biochemical mechanisms, including strong oxidative stress, intracellular $\mathrm{Ca}^{2+}$ overload, $\mathrm{pH}$ changes, mitochondrial dysfunction, inflammation, and excessive neurohormone release, that predispose cardiomyocytes to apoptosis and necrosis [44].

Hexarelin was the first GHS that demonstrated positive inotropic effects in male volunteers [45] and cardioprotective properties against heart injury [46]. in vitro, exposure of neonatal rat cardiomyocytes to hexarelin significantly decreased angiotensin II-induced apoptosis, DNA fragmentation, and increased myocyte viability [47]. The anti-apoptotic activity of hexarelin could also promote survival in $\mathrm{H} 9 \mathrm{c} 2$ cardiomyocytes subjected to doxorubicin treatment [48]. Hexarelin cardiotropic activity was also demonstrated in vivo in different experimental models of cardiac damage. Chronic hexarelin administration counteracted the ischemic damage in the heart of Zucker rats subjected to low flow I/R [49], significantly reduced cardiac fibrosis in spontaneously hypertensive rats [50], and showed protective effects against ischemic and post-ischemic ventricular dysfunction in GH-deficient [51] and hypophysectomized rats [15]. In these animal models, several clinical endpoints have been observed, including reductions of left ventricular end-diastolic pressure, coronary perfusion pressure, coronary vasculature reactivity to angiotensin II, and release of creatine kinase and prostacyclin in the heart perfusate, but an enhanced recovery of contractility. Since cardiotropic positive effects were obtained also in GH-deficient and hypophysectomized rats, these actions were specific and presumably independent of somatotropic function, probably caused by hexarelin binding to GHS-R1a and/or CD-36 receptor, a scavenger receptor expressed in cardiomyocytes and microvascular endothelial cells. The involvement of CD-36 receptor in mediating hexarelin action was supported by the lack of hexarelin cardioprotective effects in CD36-null mice and spontaneously hypertensive rats genetically deficient for CD36 [46]. Similar cardiac-positive effects were reported also in humans [52]. Binding of hexarelin to the CD-36 receptor has been proposed as a possible mechanism for its anti-atherosclerotic activities [53]. 
Other studies were performed to explore the capability of GHS to modify intracellular $\mathrm{Ca}^{2+}$ homeostasis. Muscle shortening is a function of the force of contraction, and the absence of perfusion could cause post-ischemic areas of dysfunction by causing dissociation between force development and muscle shortening. $\mathrm{I} / \mathrm{R}$ protocols induce an increase in intracellular $\left[\mathrm{Ca}^{2+}\right]$ transients, possibly due to failure in voltage-gated $\mathrm{L}$ type $\mathrm{Ca}^{2+}$ channels or alterations of sarcoplasmic reticulum $\mathrm{Ca}^{2+}$ content, or both [54]. As proposed by Ma and coworkers, GHS effects in mouse cardiomyocytes exposed to I/R injury are possibly due to several factors. First, GHS treatment administered either before or after the in vitro ischemia protocol significantly ameliorated sarcomere shortening, an index of muscle dynamics, and decreased the amplitude and the rising rate of intracellular $\left[\mathrm{Ca}^{2+}\right]$ transients, indicating the existence of a lusitropic effect [42]. These phenomena are at least in part accounted for in the restoration and maintenance of sarcoplasmic reticulum $\mathrm{Ca}^{2+}$ loading ability (SERCA2a), and therefore normal sarcoplasmic reticulum $\mathrm{Ca}^{2+}$ loading ability. This hypothesis is also supported by the modulation of phospholamban (PNL) expression [42]. PNL is a small, reversibly phosphorylated, transmembrane protein that is located in the cardiac sarcoplasmic reticulum. It plays a key regulatory role in cardiac contractility: dephosphorylated PNL modulates sarcoplasmic reticulum $\mathrm{Ca}^{2+}$ sequestration by inhibiting the SERCA2a. In this form, PLN is an inhibitor of SERCA2a, but, when phosphorylated, PLN dissociates from SERCA2a, activating the $\mathrm{Ca}^{2+}$ pump [55]. By increasing the p-PNL/PNL ratio, the GHS favor the activity of SERCA2a, thus suggesting its direct involvement in regulating specific proteins that are part of apparatus of the $\mathrm{Ca}^{2+}$ homeostasis setting [42]. It has been suggested that the cardioprotective effects of GHS in vitro could be mediated by the interaction with GHS-R1a, since the pretreatment with two GHS-R1a specific antagonists, [D-Lys3]-GHRP-6 and BIM28163, completely blocked the activity on sarcomere shortening and intracellular $\left[\mathrm{Ca}^{2+}\right]$ transients [42]. From an electrophysiological point of view, the protective actions of GHS are displayed not only by their effects on the $\mathrm{Ca}^{2+}$ control system, but also by their capability to preserve electrophysiological properties in $\mathrm{I} / \mathrm{R}$ condition. It is well known that derangements in $\mathrm{Ca}^{2+}, \mathrm{Na}^{+}, \mathrm{K}^{+}$ currents and changes in the properties of action potentials are typical of $\mathrm{I} / \mathrm{R}$ damage [56]. Hexarelin treatment in isolated cardiomyocytes from heart exposed to I/R injury increased action potential amplitude and duration, and preserved many electrophysiological properties. The ability to restore ion currents, in particular reducing inward currents $\left(\mathrm{I}_{\mathrm{CaL}}\right.$ and $\left.\mathrm{I}_{\mathrm{Na}}\right)$ and increasing the transient outward potassium current $\left(\mathrm{I}_{\mathrm{to}}\right)$, could also contribute to hexarelin positive inotropic and anti-arrhythmic effects [18].

\subsubsection{GHS Actions on Skeletal Muscle}

Skeletal muscles represent a fundamental element for human life, playing a crucial role in locomotion and respiration. Muscle wasting is related to poor quality of life, increased morbidity, and reduced survival rates in chronic disease states that predispose to poor outcomes and death [57]. The major muscle-wasting disorders are sarcopenia and cachexia [57]. Cachexia is often induced by cancer and frequently complicates the management of patients $[58,59]$. Although several researches have been focused on this topic, mechanisms underlying muscle wasting in cachexia have not been fully elucidated. Cachexia has been shown to be multifactorial and dependent both on the activation of the intracellular protein degradation apparatus, the ubiquitin $(\mathrm{Ub})$-proteasome and autophagy systems, and reduced protein synthesis [60]. Given the lack of effective treatments, GHS have been proposed as a potential therapeutic option in the management of cachexia because of their orexigenic and metabolic properties [61]. The cisplatin (CDDP)-treated rat is the experimental model frequently used for studying the molecular mechanisms causing cachexia and to establish the therapeutic value of new candidate drugs. CDDP is a cytotoxic agent widely used in antineoplastic chemotherapy; it has been characterized for its ability to induce in the rat a cachexia condition, with loss of bodyweight and, in particular, of lean muscle mass [62]. It has been demonstrated that short-term treatment with JMV2894 or hexarelin, two ligands of GHS-R1a, accelerated bodyweight gain after the initial loss induced by CDDP treatment. Bodyweight gain was not due to an adipogenic activity, but improving muscle mass 
and food efficiency, two parameters that indicate, respectively, reduced muscle atrophy and increased energy metabolism [22]. In addition, JMV2894 and hexarelin administration induced a down-regulation of muscle RING-finger protein-1 (Murf-1) E3 transcript expression, a key component of the proteasome system $[22,23]$ and an increase of the transcriptional coactivator peroxisome proliferator-activated receptor $\gamma$ coactivator- $1 \alpha$ (PGC-1 $\alpha$ ), a marker of muscle oxidative phenotype [23]. Muscle histology analysis revealed attenuated muscle damage, attested by the increased cross-sectional area of myofibers that ultimately lead to improved forelimb force [23]. The beneficial effects of GHS are linked also to their ability to maintain $\mathrm{Ca}^{2+}$ homeostasis, counteracting the detrimental effect of CDDP on isolated extensor digitorum longus (EDL) muscles. It is well known that CDDP increases the intracellular resting $\left(\mathrm{Ca}^{2+}\right)$, reduces the response to depolarizing solutions as well as to caffeine, a modulator of the RyR and affects the store-operated $\mathrm{Ca}^{2+}$ entry (SOCE), which are essential to ensure proper intracellular $\left[\mathrm{Ca}^{2+}\right]$ for muscle function [23]. Moreover, CDDP alters the expression of genes involved in $\mathrm{Ca}^{2+}$ homeostasis apparatus, such as the RyR-type 1(RyR1), the DHPR, the stromal interaction molecule (Stim1) and its main target, the $\mathrm{Ca}^{2+}$ release-activated $\mathrm{Ca}^{2+}$ modulator 1 (Orai1) [23]. JMV2894 and hexarelin effectively inhibited the $\mathrm{Ca}^{2+}$ homeostasis disruption induced by CDDP, reducing the resting intracellular $\left(\mathrm{Ca}^{2+}\right)$, recovering the myofibers responsiveness to caffeine, and thus the RyR activity, and preventing the SOCE decrease. In addition, JMV2894 resulted effective in restoring the expressions of several genes (i.e., RyR1, DHPR, Stim1, and Orai1), being in this context more effective than hexarelin, which only slightly increased the expression of these genes [23]. These different effects of two GHS both displaying agonistic activity on GHS-R1a are somehow not surprising, given the difference in their chemical structure. Indeed, it has been pointed out that minimal changes in the molecular structure of GHS can largely modify their activity; for example, a substitution of a single amino acid residue or using the L- or D-form of the same amino acid can cause loss of the orexigenic activity [63]. On the other hand, the binding sites mediating the GH-releasing and orexigenic effects of GHS are apparently very permissive, since very different peptides (from hexa- to tripeptides) have shown identical activity [63]. Some non-peptidyl GHS can affect $\mathrm{Ca}^{2+}$ homeostasis, increasing the resting intracellular $\left(\mathrm{Ca}^{2+}\right)$ differently from hexarelin and other peptidyl compounds in skeletal muscle fibers [64]. This activity could be independent of the GHS-R1a activation, as demonstrated by the use of a specific competitive antagonist of the GHS-R1a, the D-Lys-GHRP-6 [65]. JMV2894 is a peptidomimetic compound with 1,2,4-triazole scaffold as mimetic of the cis-configuration of the amide [65,66]. Although to date only one receptor for GHS has been identified [13], there is a high likelihood that other receptor/s could mediate the plethora of GHS actions, justifying also the different ability of these compounds to interfere with the $\mathrm{Ca}^{2+}$ regulation machinery. Moreover, the small molecular size of JMV2894 could suggest its interaction with the RyR and it can exert an RyR stabilizer activity, which is a characteristic of a new class of molecules called Rycals [22,67]. Rycals are capable of reducing $\mathrm{Ca}^{2+}$ leak by stabilizing the RyR channels and preserving the RyR-calstabin interaction $[68,69]$. Rycals have recently been shown to improve contractile function in both heart and skeletal muscle [70]. This peculiarity of JMV2894 could account for the positive effects on sarcoplasmic reticulum responsiveness to caffeine observed in JMV2894 treated rats [22].

Recent findings support the hypothesis that JMV2894 could prevent also mitochondrial damage [70]. The regulation of mitochondrial dynamics (fission and fusion) is critical for mitochondrial function, morphology, distribution, and turnover in muscle [71]. It is well known that one of the alterations induced by CDDP is mitochondrial fragmentation, usually related to muscle atrophy in different pathological conditions [71,72]. Muscle function is also highly dependent on communication between sarcoplasmic reticulum and mitochondria, which occurs in a bidirectional fashion by virtue also of their close spatial localization $[73,74]$. The $\mathrm{Ca}^{2+}$ released from sarcoplasmic reticulum is uptaken into adjacent mitochondria to stimulate adenosine triphosphate (ATP) production by aerobic metabolism. ATP, in turn, is required during striated muscle contraction to allow both actin-myosin cross-bridge cycling and to provide the energy to Sarco-Endoplasmatic Reticulum Calcium ATPase- (SERCA) of the sarcoplasmic reticulum during contractile relaxation. On the other 
end, retrograde mitochondrial-sarcoplasmic reticulum signaling plays a critical role in maintaining proper environmental redox potential, by the production of mitochondrial ROS, and in controlling the local $\mathrm{Ca}^{2+}$ activity. In this way, the mitochondria inhibit unwanted $\mathrm{Ca}^{2+}$ release around the $\mathrm{Ca}^{2+}$ release unit (CRU). CRU is composed of the association of transverse tubule (T-tubule) membrane containing DHPRs, flanked on either side by closely apposed RyR1 (or $\mathrm{Ca}^{2+}$ release channels), located in the terminal cisternae of the sarcoplasmic reticulum [71]. The mitochondrial juxtaposition to the CRU in skeletal muscle is allowed by mitofusin 2 (Mfn2), a transmembrane GTPase localized in both sarcoplasmic reticulum and mitochondria outer membranes. Mfn2 is a constituent of electron-dense bridges, or "tethers", connecting mitochondria to the sarcoplasmic reticulum. Tethers enable highly efficient local mitochondrial $\mathrm{Ca}^{2+}$ uptake when the $\mathrm{Ca}^{2+}$ concentrations build up in close proximity to sites of $\mathrm{Ca}^{2+}$ release [75]. CDDP administration increases Mfn2 protein expression in skeletal muscle and this effect is antagonized by GHS administration [70], suggesting that GHS can exert protective actions on mitochondrial dynamics.

\section{Conclusions}

Several pathological conditions are characterized by loss and/or impairment of muscle and by muscle wasting. Wasting, characterized by unintentional loss of body weight, encompasses both fat and lean mass and is often the result of renal and cardiac failure, cancer-induced cachexia, and sarcopenia. Dysregulation of $\mathrm{Ca}^{2+}$ homeostasis is recognized as one of the causative factors for cachexia and sarcopenia, compromising the functionality of the muscle and predisposing to poor quality of life and progression of the pathology.

Different therapeutic approaches focusing either on increasing food intake, reversing catabolism and increasing the anabolic drive of cancer patients have been proposed [76]. The few drugs approved for the treatment cachexia are progestins (medroxyprogesterone acetate and megestrol acetate). Progestins improve anorexia and increase body weight, without causing severe side effects. However, different clinical studies have demonstrated that they are not able to increase lean body mass and to improve the patient's quality of life [77].

The lack of pharmacological effective options in spite of the clinical relevance of these conditions has encouraged the investigation of known and novel GHS to identify new potential therapeutic tools. The use of in vitro cardiomyocytes and the CDDP-induced cachexia model have been useful to study the muscle-specific effects of GHS and to look into their mechanisms of action. Several evidences support the notion that GHS can prevent both cardiac and skeletal muscle damage. The myotropic effects of GHS could be in part due to their ability to prevent $\mathrm{Ca}^{2+}$ homeostasis alterations, both in terms of $\mathrm{Ca}^{2+}$ movements and expression of specific $\mathrm{Ca}^{2+}$-related proteins. On the other hand, the GHS exert protective actions also on the mitochondrial function, indicating that targeting mitochondrial dysfunction may represent an intriguing area of research to develop new pharmacological agents to counteract or limit muscle damage. The increase of mitochondrial biogenesis and the cellular antioxidant defense due to GHS treatment could represent a successful strategy in preventing muscle cachexia. To date, anamorelin, a novel ghrelin receptor agonist, is under clinical evaluation for cachexia treatment because of its ability to improve lean body mass, bodyweight, and in counteracting the anorexia-cachexia symptoms in non-small cell lung carcinoma patients. However, anamorelin administration improved muscle mass but not handgrip strength, a measure of muscle function. Further studies are needed to deepen into aspects related to calcium homeostasis regulation and mitochondrial functioning, to identify new compounds that similarly to hexarelin and JMV2894 could contribute to safeguard in vivo muscle function. Great attention must be directed also to the chemical structure of GHS, as it represents a key feature in selecting the candidate moieties targeted to counteract muscle impairment.

The Table 1 resumes some interesting GHS and their human physiological effects. 
Table 1. GHS and human physiological effects.

\begin{tabular}{|c|c|}
\hline GHS & Human Physiological Effects \\
\hline $\begin{array}{l}\text { Macrilen (JMV1843) } \\
\text { (Macimorelin) }\end{array}$ & FDA approved for diagnostic test for adult GH deficiency (AGHD). \\
\hline Anamorelin & $\begin{array}{c}\text { Phase } 3 \text { clinical trial in on small cell lung cancer: increased lean body mass and } \\
\text { bodyweight; improved some symptoms of anorexia/cachexia. }\end{array}$ \\
\hline Ulimorelin (TZP-101) & $\begin{array}{c}\text { Phase } 3 \text { clinical trial in diabetic patients: accelerated gastric emptying and improvd } \\
\text { upper gastrointestinal symptoms. }\end{array}$ \\
\hline PF-5190457 & Phase $1 \mathrm{~b}$ clinical trial in heavy drinkers: reduced alcohol-primed craving behavior. \\
\hline $\begin{array}{l}\text { MK-0677 - IBUTAMOREN } \\
\text { MESYLATE (L-163,191) }\end{array}$ & $\begin{array}{l}\text { Catabolic states: slowed nitrogen wasting and increased fat free mass and bodyweight. } \\
\text { GH-deficient adults and hemodialysis patients: increased GH, IGF-1 and prolactin levels } \\
\text { throughout the night and ACTH and cortisol levels during the first half of the night. }\end{array}$ \\
\hline ARD-07 (EP01572) & Healthy male volunteers: increased GH and IGF-1 release. \\
\hline Hexarelin & $\begin{array}{l}\text { Healthy male volunteers and GH-deficient subject: increased GH and IGF-1 secretion; } \\
\text { stimulated food intake. } \\
\text { Patients with cardiac dysfunction: cardioprotective effects. }\end{array}$ \\
\hline GHRP-2 & $\begin{array}{l}\text { GH-deficient subject: increased GH and IGF-1 secretion. } \\
\text { Healthy male volunteers and obese subjects: stimulated food intake. } \\
\text { Anorexia nervosa patients: improved bodyweight and hypoglycemia. }\end{array}$ \\
\hline EP80317 & $\begin{array}{l}\text { Preclinical studies: anti-atherosclerotic activity; anticonvulsivant activity in rat models of } \\
\text { status epilepticus; in vitro ACE-inhibiting activity }\end{array}$ \\
\hline
\end{tabular}

Author Contributions: E.B. conceived the original idea; E.B. wrote the paper with support from A.T.; L.R. and E.B. cured the graphical abstract, table and technical details; L.R., S.C., L.M., R.M. and V.L. review and editing the text.

Funding: This work was supported by Fondo di Ateneo per la Ricerca of the University of Milano-Bicocca [FAR to Antonio Torsello and Vittorio Locatelli].

Conflicts of Interest: The authors declare no competing financial interest.

\begin{tabular}{|c|c|}
\hline ATP & adenosine triphosphate \\
\hline $\mathrm{Ca}^{2+}$ & calcium \\
\hline CDDP & cisplatin (cis-dichlorodiamminoplatinum) \\
\hline CRU & $\mathrm{Ca}^{2+}$ release unit \\
\hline D-AG & des-acyl ghrelin \\
\hline DAG & diacylglycerol \\
\hline DHPR & dihydropyridine receptor \\
\hline EDL & extensor digitorum longus muscle \\
\hline $\mathrm{GH}$ & growth hormone \\
\hline GHRH & growth hormone-releasing hormone \\
\hline GPCR & G protein-coupled receptor \\
\hline GHRP & growth hormone-releasing peptides \\
\hline GHS & growth hormone secretagogues \\
\hline GHS-R1a & GHS receptor type $1 \mathrm{a}$ \\
\hline GHS-R1b & GHS receptor type $1 b$ \\
\hline GOAT & ghrelin O-acyl-transferase \\
\hline $\mathrm{I}_{\mathrm{CaL}}-\mathrm{I}_{\mathrm{Na}}$ & inward current \\
\hline IGF-I & insulin-like growth factor-I \\
\hline IP & inositol phosphate \\
\hline $\mathrm{IP}_{3}$ & inositol triphosphate \\
\hline IR & ischemia/reperfusion \\
\hline $\mathrm{I}_{\text {to }}$ & transient outward current \\
\hline LBM & lean body mass \\
\hline MBOAT & membrane- bound O-acyltrasferase \\
\hline
\end{tabular}




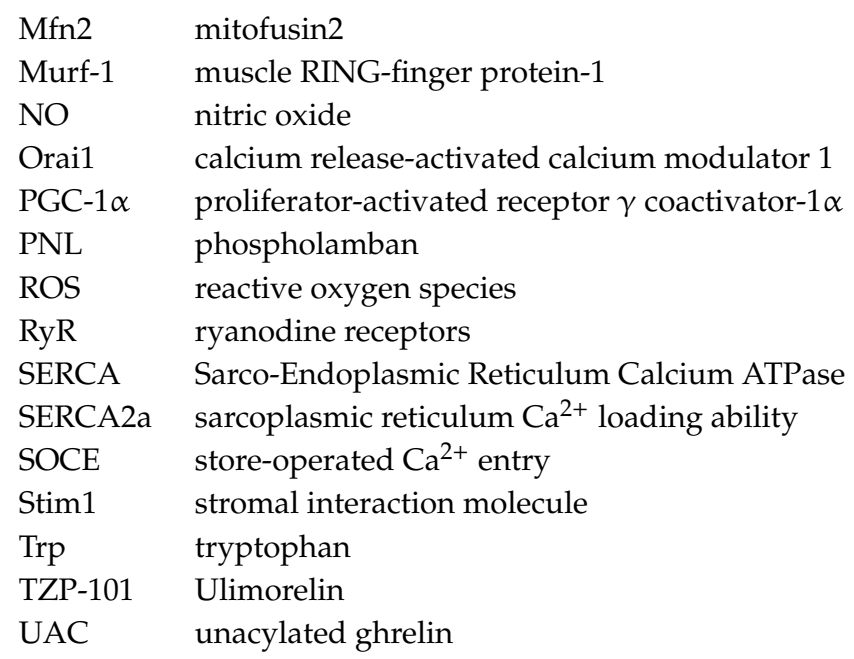

\section{References}

1. Gehlert, S.; Bloch, W.; Suhr, F. $\mathrm{Ca}^{2+}$-dependent regulations and signaling in skeletal muscle: From electro-mechanical coupling to adaptation. Int. J. Mol. Sci. 2015, 16, 1066-1095. [CrossRef]

2. Missiaen, L.; Robberecht, W.; van den Bosch, L.; Callewaert, G.; Parys, JB.; Wuytack, F.; Raeymaekers, L.; Nilius, B.; Eggermont, J.; De Smedt, H. Abnormal intracellular $\mathrm{Ca}^{2+}$ homeostasis and disease. Cell Calcium 2000, 28, 1-21. [CrossRef]

3. Agrawal, A.; Suryakumar, G.; Rathor, R. Role of defective $\mathrm{Ca}^{2+}$ signaling in skeletal muscle weakness: Pharmacological implications. J. Cell Commun Signal 2018, 12, 645-659. [CrossRef]

4. Bowers, C.Y. Growth hormone-releasing peptide (GHRP). Cell Mol. Life Sci. 1998, 54, 1316-1329. [CrossRef]

5. Arvat, E.; Broglio, F.; Aimaretti, G.; Benso, A.; Giordano, R.; Deghenghi, R.; Ghigo, E. Ghrelin and synthetic GH secretagogues. Best Pract. Res. Clin. Endocrinol. Metab. 2002, 116, 505-517. [CrossRef]

6. Kojima, M.; Hosoda, H.; Date, Y.; Nakazato, M.; Matsuo, H.; Kangawa, K. Ghrelin is a growth-hormone-releasing acylated peptide from stomach. Nature 1999, 402, 656-660. [CrossRef]

7. Alamri, B.N.; Shin, K.; Chappe, V.; Anini, Y. The role of ghrelin in the regulation of glucose homeostasis. Mol. Biol. Clin. Investig. 2016, 26, 3-11. [CrossRef]

8. Pradhan, G.; Samson, S.L.; Sun, Y. Ghrelin: Much more than a hunger hormone. Curr. Opin. Clin. Nutr. Metab. Care 2013, 16, 619-624. [CrossRef]

9. Chang, L.; Niu, F.; Chen, J.; Cao, X.; Liu, Z.; Bao, X.; Xu, Y. Ghrelin improves muscle function in dystrophin-deficient mdx mice by inhibiting NLRP3 inflammasome activation. Life Sci. 2019, 232, 116654. [CrossRef]

10. Lucchi, C.; Curia, G.; Vinet, J.; Gualtieri, F.; Bresciani, E.; Locatelli, V.; Torsello, A.; Biagini, G. Protective but not anticonvulsant effects of ghrelin and JMV-1843 in the pilocarpine model of Status epilepticus. PLoS ONE 2013, 88, e72716. [CrossRef]

11. Seminara, R.S.; Jeet, C.; Biswas, S.; Kanwal, B.; Iftikhar, W.; Sakibuzzaman, M.; Rutkofsky, I.H. The Neurocognitive Effects of Ghrelin-induced Signaling on the Hippocampus: A Promising Approach to Alzheimer's Disease. Cureus 2018, 10, e3285. [CrossRef]

12. Müller, D.; Nogueiras, R.; Andermann, M.L.; Andrews, Z.B.; Anker, S.D.; Argente, J.; Batterham, R.L.; Benoit, S.C.; Bowers, C.Y.; Broglio, F.; et al. Ghrelin. Mol. Metab. 2015, 44, 437-460. [CrossRef]

13. Howard, A.D.; Feighner, S.D.; Cully, D.F.; Arena, J.P.; Liberator, P.A.; Rosenblum, C.I.; Hamelin, M.; Hreniuk, DL.; Palyha, O.C.; Anderson, J.; et al. A receptor in pituitary and hypothalamus that functions in growth hormone release. Science 1996, 273, 974-977. [CrossRef]

14. Torsello, A.; Rossoni, G.; Locatelli, V.; De Gennaro Colonna, V.; Bernareggi, M.; Francolini, M.; Müller, E.E.; Berti, F. Hexarelin, but not growth hormone, protects heart from damage induced in vitro by calcium deprivation replenishment. Endocrine 2001, 14, 109-112. [CrossRef]

15. Torsello, A.; Bresciani, E.; Rossoni, G.; Avallone, R.; Tulipano, G.; Cocchi, D.; Bulgarelli, I.; Deghenghi, R.; Berti, F.; Locatelli, V. Ghrelin plays a minor role in the physiological control of cardiac function in the rat. Endocrinology 2003, 144, 1787-1792. [CrossRef] 
16. Xu, X.B.; Pang, J.J.; Cao, J.M.; Ni, C.; Xu, R.K.; Peng, X.Z.; Yu, X.X.; Guo, S.; Chen, M.C.; Chen, C. GH-releasing peptides improve cardiac dysfunction and cachexia and suppress stress-related hormones and cardiomyocyte apoptosis in rats with heart failure. Am. J. Physiol. Heart Circ. Physiol. 2005, 289, 1643-1651. [CrossRef]

17. Isgaard, J.; Granata, R. Ghrelin in cardiovascular disease and atherogenesis. Mol. Cell Endocrinol. 2011, 340, 59-64. [CrossRef]

18. Ma, Y.; Zhang, L.; Launikonis, B.S.; Chen, C. Growth hormone secretagogues preserve the electrophysiological properties of mouse cardiomyocytes isolated from in vitro ischemia/reperfusion heart. Endocrinology 2012, 153, 5480-5490. [CrossRef]

19. McDonald, H.; Peart, J.; Kurniawan, N.; Galloway, G.; Royce, S.; Samuel, C.; Chen, C. Hexarelin treatment preserves myocardial function and reduces cardiac fibrosis in a mouse model of acute myocardial infarction. Physiol. Rep. 2018, 66, e13699. [CrossRef]

20. Broglio, F.; Guarracino, F.; Benso, A.; Gottero, C.; Prodam, F.; Granata, R.; Avogadri, E.; Muccioli, G.; Deghenghi, R.; Ghigo, E. Effects of acute hexarelin administration on cardiac performance in patients with coronary artery disease during by-pass surgery. Eur. J. Pharmacol. 2002, 448, 193-200. [CrossRef]

21. Imazio, M.; Bobbio, M.; Broglio, F.; Benso, A.; Podio, V.; Valetto, M.R.; Bisi, G.; Ghigo, E.; Trevi, G.P. $\mathrm{GH}$-independent cardiotropic activities of hexarelin in patients with severe left ventricular dysfunction due to dilated and ischemic cardiomyopathy. Eur. J. Heart Fail 2002, 44, 185-191. [CrossRef]

22. Bresciani, E.; Rizzi, L.; Molteni, L.; Ravelli, M.; Liantonio, A.; Ben Haj Salah, K.; Fehrentz, J.A.; Martinez, J.; Omeljaniuk, RJ.; Biagini, G.; et al. JMV2894, a novel growth hormone secretagogue, accelerates body mass recovery in an experimental model of cachexia. Endocrine 2017, 58, 106-114. [CrossRef]

23. Conte, E.; Camerino, G.M.; Mele, A.; De Bellis, M.; Pierno, S.; Rana, F.; Fonzino, A.; Caloiero, R.; Rizzi, L.; Bresciani, E.; et al. Growth hormone secretagogues prevent dysregulation of skeletal muscle calcium homeostasis in a rat model of cisplatin-induced cachexia. J. Cachexia Sarcopenia Muscle 2017, 88, 386-404. [CrossRef]

24. Virdis, A.; Lerman, L.O.; Regoli, F.; Ghiadoni, L.; Lerman, A.; Taddei, S. Human Ghrelin: A Gastric Hormone with Cardiovascular Properties. Curr. Pharm. Des. 2016, 22, 52-58. [CrossRef]

25. Chen, J.; Splenser, A.; Guillory, B.; Luo, J.; Mendiratta, M.; Belinova, B.; Halder, T.; Zhang, G.; Li, Y.P.; Garcia, J.M. Ghrelin prevents tumour- and cisplatin-induced muscle wasting: Characterization of multiple mechanisms involved. J. Cachexia Sarcopenia Muscle 2015, 66, 132-143. [CrossRef]

26. Rivier, J.; Spiess, J.; Thorner, M.O.; Vale, W. Characterization of a growth hormone-releasing factor from a human pancreatic islet tumor. Nature 1982, 300, 276-278. [CrossRef]

27. Bowers, C.Y.; Momany, F.A.; Reynolds, G.A.; Hong, A. On the in vitro and in vivo activity of a new synthetic hexapeptide that acts on the pituitary to specifically release growth hormone. Endocrinology 1984, 114, 1537-1545. [CrossRef]

28. Gaylinn, B.D.; Harrison, J.K.; Zysk, J.R.; Lyons, C.E.; Lynch, K.R.; Thorner, M.O. Molecular cloning and expression of a human anterior pituitary receptor for growth hormone-releasing hormone. Mol. Endocrinol. $1993,7,77-84$.

29. Cheng, K.; Chan, W.W.S.; Barreto, A.; Convey, E.M.; Smith, R.G. The synergistic effects of His-D-Trp-Ala-Trp-D-Phe-Lys-NH2 on growth hormone (GH)-releasing factor-stimulated GH release and intracellular adenosine 3', 5'-monophosphate accumulation in rat primary pituitary cell culture. Endocrinology 1989, 124, 2791-2798. [CrossRef]

30. Bowers, C.Y.; Sartor, A.O.; Reynolds, G.A.; Badger, T.M. On the actions of the growth hormone-releasing hexapeptide, GHRP. Endocrinology 1991, 128, 2027-2035. [CrossRef]

31. Massoud, A.F.; Hindmarsh, P.C.; Matthews, D.R.; Brook, C.G. The effect of repeated administration of hexarelin, a growth hormone releasing peptide, and growth hormone releasing hormone on growth hormone responsivity. Clin. Endocrinol. 1996, 44, 555-562. [CrossRef]

32. Smith, R.G. Development of growth hormone secretagogues. Endocr. Rev. 2005, 26, 346-360. [CrossRef]

33. Huhn, W.C.; Hartman, M.L.; Pezzoli, S.S.; Thorner, M.O. Twenty-four-hour growth hormone (GH)-releasing peptide (GHRP) infusion enhances pulsatile GH secretion and specifically attenuates the response to a subsequent GHRP bolus. J. Clin. Endocrinol. Metab. 1993, 76, 1202-1208.

34. Navarro, G.; Aguinaga, D.; Angelats, E.; Medrano, M.; Moreno, E.; Mallol, J.; Cortés, A.; Canela, EI.; Casadó, V.; McCormick, P.J.; et al. A Significant Role of the Truncated Ghrelin Receptor GHS-R1b in Ghrelin-induced Signaling in Neurons. J. Biol. Chem. 2016, 291, 13048-13062. [CrossRef] 
35. Delhanty, P.J.; Neggers, S.J.; van der Lely, A.J. Should we consider des-acyl ghrelin as a separate hormone and if so, what does it do? Front. Horm. Res. 2014, 42, 163-174.

36. Currow, D.C.; Maddocks, M.; Cella, D.; Muscaritoli, M. Efficacy of Anamorelin, a Novel Non-Peptide Ghrelin Analogue, in Patients with Advanced Non-Small Cell Lung Cancer (NSCLC) and Cachexia-Review and Expert Opinion. Int. J. Mol. Sci. 2018, 19, 3471. [CrossRef]

37. Shaw, M.; Pediconi, C.; McVey, D.; Mondou, E.; Quinn, J.; Chamblin, B.; Rousseau, F. Safety and efficacy of ulimorelin administered postoperatively to accelerate recovery of gastrointestinal motility following partial bowel resection: Results of two randomized, placebo-controlled phase 3 trials. Dis. Colon. Rectum. 2013, 56, 888-897. [CrossRef]

38. Lee, M.R.; Tapocik, J.D.; Ghareeb, M.; Schwandt, M.L.; Dias, A.A.; Le, A.N.; Cobbina, E.; Farinelli, L.A.; Bouhlal, S.; Farokhnia, M.; et al. The novel ghrelin receptor inverse agonist PF-5190457 administered with alcohol: Preclinical safety experiments and a phase 1b human laboratory study. Mol. Psychiatry 2018, 1. [CrossRef]

39. Stangl, M.K.; Böcker, W.; Chubanov, V.; Ferrari, U.; Fischereder, M.; Gudermann, T.; Hesse, E.; Meinke, P.; Reincke, M.; Reisch, N.; et al. Sarcopenia-Endocrinological and Neurological Aspects. Exp. Clin. Endocrinol. Diabetes 2019, 127, 8-22.

40. Martin, L.; Birdsell, L.; Macdonald, N.; Reiman, T.; Clandinin, M.T.; McCargar, L.J.; Murphy, R.; Ghosh, S.; Sawyer, MB.; Baracos, VE. Cancer cachexia in the age of obesity: Skeletal muscle depletion is a powerful prognostic factor, independent of body mass index. J. Clin. Oncol. 2013, 31, 1539-1547. [CrossRef]

41. Sun, Q.; Ma, Y.; Zhang, L.; Zhao, Y.F.; Zang, W.J.; Chen, C. Effects of GH secretagogues on contractility and $\mathrm{Ca}^{2+}$ homeostasis of isolated adult rat ventricular myocytes. Endocrinology 2010, 151, 4446-4454. [CrossRef]

42. Ma, Y.; Zhang, L.; Edwards, J.N.; Launikonis, B.S.; Chen, C. Growth hormone secretagogues protect mouse cardiomyocytes from in vitro ischemia/reperfusion injury through regulation of intracellular calcium. PLoS ONE 2012, 77, e35265. [CrossRef]

43. Shimokawa, H.; Yasuda, S. Myocardial ischemia: Current concepts and future perspectives. J. Cardiol. 2008, 52, 67-78. [CrossRef]

44. Yang, Q.; He, G.W.; Underwood, M.J.; Yu, C.M. Cellular and molecular mechanisms of endothelial ischemia/reperfusion injury: Perspectives and implications for postischemic myocardial protection. Am. J. Transl. Res. 2016, 88, 765-777.

45. Bisi, G.; Podio, V.; Valetto, M.R.; Broglio, F.; Bertuccio, G.; Del Rio, G.; Arvat, E.; Boghen, M.F.; Deghenghi, R.; Muccioli, G.; et al. Acute cardiovascular and hormonal effects of GH and hexarelin, a synthetic GH-releasing peptide, in humans. J. Endocrinol. Invest. 1999, 22, 266-272. [CrossRef]

46. Mao, Y.; Tokudome, T.; Kishimoto, I. The cardiovascular action of hexarelin. J. Geriatr. Cardiol. 2014, 11, $253-258$.

47. Pang, J.J.; Xu, R.K.; Xu, X.B.; Cao, J.M.; Ni, C.; Zhu, W.L.; Asotra, K.; Chen, M.C.; Chen, C. Hexarelin protects rat cardiomyocytes from angiotensin II-induced apoptosis in vitro. Am. J. Physiol. Heart Circ. Physiol. 2004, 286, H1063-H1069. [CrossRef]

48. Filigheddu, N.; Fubini, A.; Baldanzi, G.; Cutrupi, S.; Ghè, C.; Catapano, F.; Broglio, F.; Bosia, A.; Papotti, M.; Muccioli, G.; et al. Hexarelin protects $\mathrm{H} 9 \mathrm{c} 2$ cardiomyocytes from doxorubicin-induced cell death. Endocrine 2001, 14, 113-119. [CrossRef]

49. De Gennaro-Colonna, V.; Rossoni, G.; Cocchi, D.; Rigamonti, A.E.; Berti, F.; Muller, E.E. Endocrine, metabolic and cardioprotective effects of hexarelin in obese Zucker rats. J. Endocrinol. 2000, 166, 529-536. [CrossRef]

50. Berti, F.; Müller, E.; De Gennaro Colonna, V.; Rossoni, G. Hexarelin exhibits protective activity against cardiac ischaemia in hearts from growth hormone-deficient rats. Growth Horm. IGF Res. 1998, 8, 149-152. [CrossRef]

51. Xu, X.; Ding, F.; Pang, J.; Gao, X.; Xu, R.K.; Hao, W.; Cao, J.M.; Chen, C. Chronic administration of hexarelin attenuates cardiac fibrosis in the spontaneously hypertensive rat. Am. J. Physiol. Heart Circ. Physiol. 2012, 303, H703-H711. [CrossRef]

52. Mosa, R.M.; Zhang, Z.; Shao, R.; Deng, C.; Chen, J.; Chen, C. Implications of ghrelin and hexarelin in diabetes and diabetes-associated heart diseases. Endocrine 2015, 49, 307-323. [CrossRef]

53. Avallone, R.; Demers, A.; Rodrigue-Way, A.; Bujold, K.; Harb, D.; Anghel, S.; Wahli, W.; Marleau, S.; Ong, H.; Tremblay, A. A growth hormone-releasing peptide that binds scavenger receptor CD36 and ghrelin receptor up-regulates sterol transporters and cholesterol efflux in macrophages through a peroxisome proliferator-activated receptor gamma-dependent pathway. Mol. Endocrinol. 2006, 20, 3165-3178. [CrossRef]

54. Bers, D.M. Cardiac excitation-contraction coupling. Nature 2002, 415, 198-205. [CrossRef] 
55. MacLennan, D.H.; Kranias, E.G. Phospholamban: A crucial regulator of cardiac contractility. Nat. Rev. Mol. Cell Biol. 2003, 44, 566-577. [CrossRef]

56. Murphy, E.; Steenbergen, C. Mechanisms underlying acute protection from cardiac ischemia-reperfusion injury. Physiol. Rev. 2008, 88, 581-609. [CrossRef]

57. Sakuma, K.; Aoi, W.; Yamaguchi, A. Molecular mechanism of sarcopenia and cachexia: Recent research advances. Pflug. Arch. 2017, 469, 573-591. [CrossRef]

58. Mantovani, G.; Madeddu, C. Cancer cachexia: Medical management. Support Care Cancer 2010, 18, 1-9. [CrossRef]

59. Madeddu, C.; Mantovani, G.; Gramignano, G.; Astara, G.; Macciò, A. Muscle wasting as main evidence of energy impairment in cancer cachexia: Future therapeutic approaches. Future Oncol. 2015, 11, 2697-2710. [CrossRef]

60. Argilés, J.M.; Busquets, S.; Stemmler, B.; López-Soriano, F.J. Cancer cachexia: Understanding the molecular basis. Nat. Rev. Cancer. 2014, 14, 754-762. [CrossRef]

61. Colldén, G.; Tschöp, M.H.; Müller, T.D. Therapeutic Potential of Targeting the Ghrelin Pathway. Int. J. Mol. Sci. 2017, 18, 798. [CrossRef]

62. Le Bricon, T.; Gugins, S.; Cynober, L.; Baracos, V.E. Negative impact of cancer chemotherapy on protein metabolism in healthy and tumor-bearing rats. Metabolism 1995, 44, 1340-1348. [CrossRef]

63. Torsello, A.; Luoni, M.; Schweiger, F.; Grilli, R.; Guidi, M.; Bresciani, E.; Deghenghi, R.; Müller, EE.; Locatelli, V. Novel hexarelin analogs stimulate feeding in the rat through a mechanism not involving growth hormone release. Eur. J. Pharmacol. 1998, 360, 123-129. [CrossRef]

64. Liantonio, A.; Gramegna, G.; Carbonara, G.; Sblendorio, V.T.; Pierno, S.; Fraysse, B.; Giannuzzi, V.; Rizzi, L.; Torsello, A.; Camerino, D.C. Growth hormone secretagogues exert differential effects on skeletal muscle calcium homeostasis in male rats depending on the peptidyl/nonpeptidyl structure. Endocrinology 2013, 154, 3764-3775. [CrossRef]

65. Moulin, A.; Demange, L.; Bergé, G.; Gagne, D.; Ryan, J.; Mousseaux, D.; Heitz, A.; Perrissoud, D.; Locatelli, V.; Torsello, A.; et al. Toward potent ghrelin receptor ligands based on trisubstituted 1,2,4-triazole structure. 2. Synthesis and pharmacological in vitro and in vivo evaluations. J. Med. Chem. 2007, 50, 5790-5806. [CrossRef]

66. Demange, L.; Boeglin, D.; Moulin, A.; Mousseaux, D.; Ryan, J.; Bergé, G.; Gagne, D.; Heitz, A.; Perrissoud, D.; Locatelli, V.; et al. Synthesis and pharmacological in vitro and in vivo evaluations of novel triazole derivatives as ligands of the ghrelin receptor. J. Med. Chem. 2007, 50, 1939-1957. [CrossRef]

67. Marks, A.R. Calcium cycling proteins and heart failure: Mechanisms and therapeutics. J. Clin. Invest. 2013, 123, 46-52. [CrossRef]

68. Bellinger, A.M.; Reiken, S.; Dura, M.; Murphy, P.W.; Deng, S.X.; Landry, D.W.; Nieman, D.; Lehnart, S.E.; Samaru, M.; LaCampagne, A.; et al. Remodeling of ryanodine receptor complex causes "leaky" channels: A molecular mechanism for decreased exercise capacity. Proc. Natl. Acad. Sci. USA 2008, 105, 2198-2202. [CrossRef]

69. Andersson, D.C.; Betzenhauser, M.J.; Reiken, S.; Meli, A.C.; Umanskaya, A.; Xie, W.; Shiomi, T.; Zalk, R.; Lacampagne, A.; Marks, A.R. Ryanodine receptor oxidation causes intracellular calcium leak and muscle weakness in aging. Cell Metab. 2011, 14, 196-207. [CrossRef]

70. Sirago, G.; Conte, E.; Fracasso, F.; Cormio, A.; Fehrentz, J.A.; Martinez, J.; Musicco, C.; Camerino, G.M.; Fonzino, A.; Rizzi, L.; et al. Growth hormone secretagogues hexarelin and JMV2894 protect skeletal muscle from mitochondrial damages in a rat model of cisplatin-induced cachexia. Sci. Rep. 2017, 7, 13017. [CrossRef]

71. Romanello, V.; Guadagnin, E.; Gomes, L.; Roder, I.; Sandri, C.; Petersen, Y.; Milan, G.; Masiero, E.; Del Piccolo, P.; Foretz, M.; et al. Mitochondrial fission and remodelling contributes to muscle atrophy. EMBO J. 2010, 29, 1774-1785. [CrossRef]

72. Fontes-Oliveira, C.C.; Busquets, S.; Toledo, M.; Penna, F.; Paz Aylwin, M.; Sirisi, S.; Silva, A.P.; Orpí, M.; García, A.; Sette, A.; et al. Mitochondrial and sarcoplasmic reticulum abnormalities in cancer cachexia: Altered energetic efficiency? Biochim. Biophys. Acta 2013, 1830, 2770-2778. [CrossRef]

73. Rossi, A.E.; Boncompagni, S.; Dirksen, R.T. Sarcoplasmic Reticulum-Mitochondrial Symbiosis: Bidirectional Signaling in Skeletal Muscle. Exerc. Sport Sci. Rev. 2009, 37, 29-35. [CrossRef] 
74. Pietrangelo, L.; D’Incecco, A.; Ainbinder, A.; Michelucci, A.; Kern, H.; Dirksen, R.T.; Boncompagni, S.; Protasi, F. Age-dependent uncoupling of mitochondria from $\mathrm{Ca}^{2+}$ release units in skeletal muscle. Oncotarget 2015, 6, 35358-35371. [CrossRef]

75. Ainbinder, A.; Boncompagni, S.; Protasi, F.; Dirksen, R.T. Role of Mitofusin-2 in mitochondrial localization and calcium uptake in skeletal muscle. Cell Calcium 2015, 57, 14-24. [CrossRef]

76. Argilés, J.M.; López-Soriano, F.X.; Stemmler, B.; Busquets, S. Therapeutic strategies against cancer cachexia. Eur. J. Transl. Myol. 2019, 29, 7960. [CrossRef]

77. Ruiz-García, V.; López-Briz, E.; Carbonell-Sanchis, R.; Bort-Martí, S.; Gonzálvez-Perales, J.L. Megestrol acetate for cachexia-anorexia syndrome. A systematic review. J. Cachexia Sarcopenia Muscle 2018, 9, 444-452. [CrossRef]

(C) 2019 by the authors. Licensee MDPI, Basel, Switzerland. This article is an open access article distributed under the terms and conditions of the Creative Commons Attribution (CC BY) license (http://creativecommons.org/licenses/by/4.0/). 